\title{
ECOLOGY
}

\section{Dirhinus giffardii (Hymenoptera: Chalcididae), parasitoid affecting Black Soldier Fly production systems in West Africa}

\author{
Emilie Devic, Pierre-Olivier Maquart \\ Institute of Aquaculture, University of Stirling, UK
}

\begin{abstract}
Interest for insect farming is currently growing globally. Conditions in West Africa appear suitable for developing such farming systems that can benefit communities by improving livelihoods, food and feed security or sanitation. In Ghana and Mali, the Black Soldier Fly (Hermetia illucens Linnaeus, 1758) is being produced for waste recycling and animal feed. In a two stages process (egg and larvae production), egg production was hampered by a pupal parasitoid, Dirhinus giffardii Silvestri, 1913 (Hymenoptera: Chalcididae), which reduced future broodstock by almost $72 \%$. This is the first time $D$. giffardii is reported as a parasitoid of $H$. illucens pupae and one of the first reports of parasitism in this commercially important fly species. The introduction of precautionary measures is highly recommended for the success of $H$. illucens production systems in West Africa.
\end{abstract}

Correspondence: Emilie Devic, Institute of Aquaculture, University of Stirling, Stirling, Stirlingshire, FK9 4LA, UK.

Tel.: +44.1786.467874.

E-mail: e.d.devic@stir.ac.uk

Key words: New record; chalcid wasp; host; Stratiomyidae; Hermetia illucens; Ghana.

Acknowledgements: this finding is part of the research outcomes of the EU FP7 PROteINSECT project (grant agreement $n^{\circ} 312084$ ). Special thanks go to N'Golopé Koné (Mali), Mr. H. E. Davis (University of Ghana) and Mr. J. Anankware (KNUST) for their help to identify the parasitoid species, M. Kenis (CABI) and D. Little for their comments on the manuscript.

Contributions: the authors contributed equally.

Conflict of interest: the authors declare no potential conflict of interest.

Received for publication: 15 June 2015.

Revision received: 11 September 2015.

Accepted for publication: 15 September 2015.

This work is licensed under a Creative Commons Attribution NonCommercial 3.0 License (CC BY-NC 3.0).

(C) Copyright E. Devic and P.-O. Maquart, 2015

Licensee PAGEPress, Italy

Entomologia 2015; 3:284

doi:10.4081/entomologia.2015.284

\section{Short Communication}

The Black Soldier Fly (BSF), Hermetia illucens Linnaeus, 1758 (Diptera: Stratiomyidae), is an insect offering biological characteristics that can benefit Low and Medium Income Countries. BSF larvae can transform low-value organic materials, such as municipal and household wastes, agro-industrial by-products or wastes into nutrientrich biomass (Lardé, 1990; St-Hilaire et al., 2007; Hem et al., 2008; Diener, 2010; Kalová \& Borkovcová, 2010). Frass, resulting from the bioconversion process, is also a valuable by-product having value as an organic fertilizer (Choi et al., 2009; Green \& Popa, 2012). A semi-controlled pilot-scale BSF farming system was developed in Greater Accra region (Ghana, West Africa) as a demonstration that local production of fly larvae can benefit farmers and support sustainable practices, such as animal feed production (van Huis et al., 2013). Production was separated in two units subjected to natural environment conditions (Caruso et al., 2013): the insectarium consisting in fly adult rearing and egg production and the larvarium for the larvae and pupae production. Hermetia illucens is a species well adapted to the climatic conditions of South Ghana where it has been found in rural areas (W. Berger, personal communication, June 2013). Its life cycle and breeding techniques are well described (Sheppard et al., 2002; Caruso et al., 2013), however application and adaptation to different environments can uncover unexpected challenges. In the case presented here, the identification of Dirhinus giffardii Silvestri, 1913 (Hymenoptera, Chalcididae), a parasitoid wasp originally described from Nigeria (West Africa), has been the key to understand the low emergence rate of the imagos (adult BSF) from the pupae obtained in rearing conditions (expected broodstock).

The presence of the parasitoid wasp was first noticed while adults were freely moving among BSF pupae; they simulate death when touched, which makes them easy to capture (Dresner, 1954; Narendran \& Amareswara Rao, 1987). Dissection of non-emergent BSF pupae revealed the presence of parasitoid larvae and pupae (Figure 1); only one immature wasp was recorded per host pupae as reported in other species (Wang and Messing, 2004a; El-Husseini et al., 2008). The species has been identified morphologically at the University of Ghana, Accra, from adults wasps captured after emergence from BSF pupae (H.E. Davis, personal communication, June 2014). To measure the incidence of the parasitoid on the BSF population, 13 randomly choosen batches containing between 90 and 3422 host pupae and produced between April and June 2014, have been sampled (a production batch is produced every 2 days in order to repopulate the broodstock). Pupae were placed in plastic containers closed by lids allowing air circulation, kept under natural temperature and humidity conditions (respectively $29.0 \pm 2.3^{\circ} \mathrm{C}$ and $83.7 \pm 10.9 \%$ ) and batches were kept for observation during 3 to 5 weeks. During this 
time, BSF as well as some parasitoids emerged, and were daily removed from the containers. Non-emerged pupae were further dissected to detect the presence of unhatched parasitoids. On average, only $26.9 \%$ $(\mathrm{SD}=19.2)$ of the pupae turned into BSF adults emerging after $10 \pm 2$ days. $52.3 \%(\mathrm{SD}=17.0)$ pupae contained a parasitoid (emerged or not emerged) and $20.7 \%(\mathrm{SD}=12.3)$ died for unknown reason. The most affected batch ( $\mathrm{n}=1116$ pupae) contained $70.7 \%$ of pupae parasitized by $D$. giffardii and only $8.5 \%$ of the flies emerged.

Silvestri (1913) was the first to describe this chalcidid wasp from the pupae of the fruit fly Ceratitis anonae Graham (Diptera: Tephritidae) collected in Nigeria. Since then, it has been introduced in many other countries as a biological control agent against tephritid flies, fruit pests of great economic importance (White \& Elson-Harris, 1992; Wang \& Messing, 2004c; Mohamed, 2007). Dirhinus giffardii can be considered as a generalist parasitoid as it can be hosted by many species of several families of Diptera (Tephritidae, Glossinidae and Muscidae) and Lepidoptera (Noctuidae) (Noyes, 2014). In line with the behaviour described by Wang and Messing (2004a), observations made in Ghana suggest that female parasitoid attacked fully formed BSF pupae. Indeed, when prepupae were isolated (placed in a container parasitoidproof) until emergence of the imago, $98.5 \%$ of the pupae $(n=1289)$ turned into adult flies. Some species of Chalcis parasitise Stratiomyidae, however their strategy consists in ovipositing directly into the egg or the larvae of the host (Bouček \& Halstead, 1997). At the same time and on the same site in Ghana, D. giffardii was also found attacking housefly pupae (M. Kenis, personal communication, March 2014), which is reported as a common host for the parasitoid (Noyes 2014). However, D. giffardii's reproductive strategy consists in attacking large host species in order to produce larger offspring and gain in fitness (Narendran \& Amareswara Rao, 1987; Wang \& Messing, 2004b), explaining the selection of $H$. illucens as host. Dirhinus giffardii's host selection strategy depends also on the age of its host; according to Wang and Messing (2004a) offsprings' survival rate is greater when parasiting two to three days old puparia of Ceratitis capitata Wiedemann (Diptera: Tephritidae). Under laboratory conditions $\left(25-27^{\circ} \mathrm{C} ; 50-60 \% \mathrm{RH}\right)$, El-Husseini et al. (2008) found that $D$. giffardii adults live for about 19 days and a single female deposits between 13 and 58 eggs. Furthermore, the complete life cycle of $D$. giffardii (from egg to adult) takes 16 to 20 days in tropical Africa (Silvestri, 1913).

Despite the numerous studies and uses of BSF for waste bioconversion or animal feed production, parasitism has been very rarely described and litterature reported only Trichopria sp. (Hymenoptera: Diapriidae) as a parasitoid of the BSF (Bradley et al., 1984). The ptero-

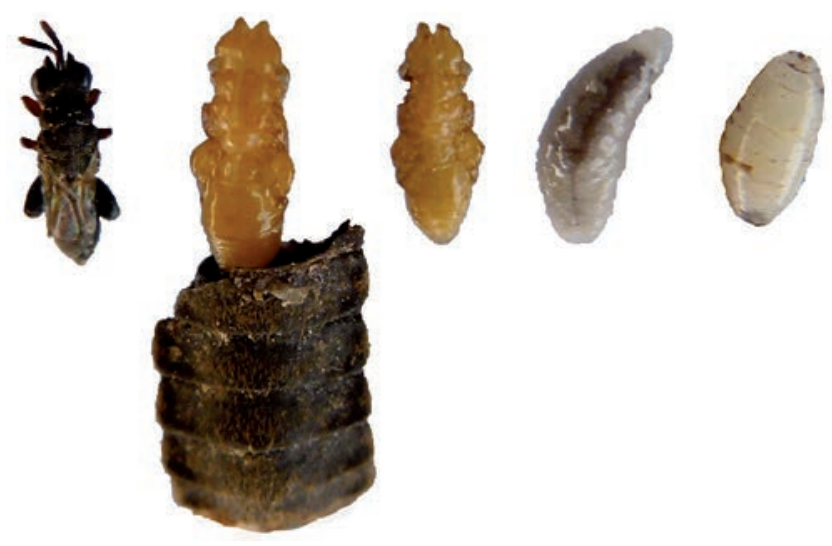

Figure 1. Dirhinus giffardii specimens collected in Hermetia illucens pupae in Ghana, showing different stages of development (from left to right, one adult, two pupae and two larvae). malid Pachycrepoideus vindemiae Rondani (Hymenoptera: Pteromalidae) another polyphagous parasitoid of fly pupae, is reported from BSF in the Universal Chalcidoidea database (Noyes, 2014) but the original reference does not clearly mention this host-parasitoid association (Pickens et al., 1975). Interestingly, $P$. vindemiae attacked the housefly, Musca domestica Linnaeus (Diptera: Muscidae), at the same site in Ghana but it was not recorded on BSF (M. Kenis, personal communication, March 2014).

The production of large and consistent amounts of BSF eggs is one of the main bottlenecks of sustainable and successful mass production systems, and biotic and abiotic factors affecting broodstock husbandry are yet to be fully understood (Gobbi, 2012). In the case reported here, the parasitoid $D$. giffardii represents an additional constraint to egg production. More generally, it can be considered as a significant threat for a BSF farming system in the countries where it occurs. During the visit of another pilot farm in Mali (West Africa), the presence and strong activity of a parasitoid wasp similar to $D$. giffardii (but not formally identified) within the BSF system was also observed. Although the incidence of the wasp on overall BSF rearing system could not be assessed, it is assumed to be the main cause of the adult population decline impacting directly on the egg production results. Systems developed in Ghana and Mali are semi-controlled systems designed for Low and Medium Income Countries but they are widely exposed to environmental variations and risks (temperature changes, storms, pollution, competition, predation and parasitism). Dirhinus giffardii is able to impact strongly on the productivity of such a system, therefore, the introduction of precautionary measures is strongly recommended. For instance, BSF prepupae and pupae could be placed in adapted rearing structures, preventing the parasitoid wasp to enter (i.e. cages or trays covered with small size net mesh). Protective measure could be applied until the emergence of the imagos or until pupae vulnerability decreases. On the other hand, the interaction host-parasitoid should be further investigate in order to develop sustainable and cost-effective preventive methods to apply.

\section{References}

BOUČEK Z., HALSTEAD J.A., 1997 - Chapter 6: Chalcididae. In: Gibson G.A.P., Huber J.T., Woolley J.B., (Ed.). Annotated keys to the genera of Nearctic Chalcidoidea (Hymenoptera). NRC Research Press, Ottawa, pp 151-164.

BRADLEY S.W., BOOTH D.C., SHEPPARD D.C., 1984 - Parasitism of the black soldier fly by Trichopria sp. (Hymenoptera: Diapriidae) in poultry houses. Environ. Entomol. 13: 451-454.

CARUSO D., DEVIC E., SUBAMIA I.W., TALAMOND P., BARAS E., 2013 Technical handbook of domestication and production of Diptera Black Soldier Fly (BSF) Hermetia illucens, Stratiomyidae. IRD Edition, Marseille.

CHOI Y.C., CHOI J.Y., KIM J.G., KIM M.S., KIM W.T., PARK K.H., BAE S.W., JEONG G.S., 2009 - Potential usage of food waste as a natural fertilizer after digestion by Hermetia illucens (Diptera: Stratiomyidae). Int. J. Indust. Entomol. 19: 171-174.

DIENER S., 2010 - Valorisation of organic solid waste using the Black Soldier Fly, Hermetia illucens, in low and middle income countries. PhD thesis, ETH Zürich.

DRESNER E, 1954 - Observations on the biology and habits of pupal parasites of the oriental fruit fly. In: Proceedings, Hawaiian Entomological Society XV: 299-310.

EL-HUSSEINI M.M., AGAMY E.A., SAAFAN M.H., ABD EL-KHALEK W.M., 2008 - On the biology of Dirhinus giffardii (Silvestri) (Hymenoptera: Chalcididae) parasitizing pupae of the peach fruit fly, Bactrocera zonata (Saunders) (Diptera: Tephritidae) in Egypt. Egypt. J. Biol. Pest Co. 18: 391-396. 
GOBBI F.P., 2012 - Biología reproductiva y caracterización morfológica de los estadios larvarios de Hermetia illucens (L., 1758) (Diptera: Stratiomyidae). Bases para su producción masiva en Europa. PhD Thesis, Universidad de Alicante.

GREEN T.R., POPA R., 2012 - Enhanced ammonia content in compost leachate processed by black soldier fly larvae. Appl. Biochem. Biotechnol. 166: 1381-1387.

HEM S., TOURE S., SAGBLA C., LEGENDRE M., 2008 - Bioconversion of palm kernel meal for aquaculture: Experiences from the forest region (Republic of Guinea). Afr. J. Biotechnol. 7: 1192-1198.

VAN HUIS A., VAN ITTERBEECK J., KLUNDER H.C., MERTENS E., HALLORAN A., MUIR G., VANTOMME P., 2013 - Edible insects - Future prospects for food and feed security. FAO Forestry Paper 71.

KALOVÁ M., BORKOVCOVÁ M., 2010 - Waste Management and Hermetia illucens. In: MendelNet2010, Proceedings of International Ph.D. students Conference, Czech Republic: 524-527.

LARDÉ G., 1990 - Recycling of coffee pulp by Hermetia illucens (Diptera: Stratiomyidae) Larvae. Biol. Wastes 33: 307-310.

MOHAMED S.M.A., 2007 - Studies on Dirhinus giffardii Silvestri (Hymenoptera: Chalcididae) a parasitoid of Bactrocera zonata (Saunders) pupae (Diptera: Tephritidae) in Egypt. Al-Azhar J. Agric. Sci. Sector Res. 3: 141-153.

NARENDRAN T.C., AMARESWARA RAO S., 1987 - Biosystematics of Chalcididae (Chalcidoidea: Hymenoptera). Proc. Ind. Acad. Sci. (Anim. Sci.) 5: 543-550.

NOYES J.S., 2014 - Universal chalcidoidea database. Avaliable from: http://www.nhm.ac.uk/chalcidoids.
PICKENS L.G., MILLER R.W., CENTALA M.M., 1975 - Biology, population dynamics and host finding efficiency of Pachycrepoideus vindemiae in a box stall and poultry house. Environ. Entomol. 4 : 975-979.

SHEPPARD D.C., TOMBERLIN J.K., JOYCE J.A., KISER B.C., SUMNER S.M., 2002 - Rearing methods for the black soldier fly (Diptera: Stratiomyidae). J. Med. Entomol. 39: 695-698.

SILVESTRI F., 1913 - Viaggio in Africa per cercare parassiti di mosche dei frutti. Boll. Lab. Zool. Sc. Agri. Portici. VIII.

ST-HILAIRE S., CRANFILL K., MCGUIRE M.A., MOSLEY E.E., TOMBERLIN J.K., NEWTON G.L., SEALEY W., SHEPPARD D.C., IRVING S., 2007 - Fish offal recycling by the black soldier fly produces a foodstuff high in omega-3 fatty acids. J. World Aquac. Soc. 38: 309-313.

WANG X.G., MESSING R.H., 2004a - Fitness consequences of body-sizedependent host species selection in a generalist ectoparasitoid. Behav. Ecol. Sociobiol. 56: 513-522.

WANG X.G., MESSING R.H., 2004b - Two different life-history strategies determine the competitive outcome between Dirhinus giffardii (Chalcididae) and Pachycrepoideus vindemmiae (Pteromalidae), ectoparasitoids of cyclorrhaphous Diptera. Bull. Entomol. Res. 94: 473-480.

WANG X.G., MESSING R.H., 2004c - Potential interactions between pupal and egg- or larval-pupal parasitoids of tephritid fruit flies. Environ. Entomol. 33: 1313-1320.

WHITE I.M., ELSON-HARRIS M.M., 1992 - Fruit flies of economic significance: their identification and bionomics, CAB International, Wallingford, England. 